\title{
Temporomandibular Joint Disorders in Children and Related Comorbidities
}

\author{
Guhan Dergin* and Sertac Aktop \\ Marmara University Faculty of Dentistry Department of Oral and Maxillofacial Surgery, Buyuk Ciftlik, Turkey
}

\begin{abstract}
Condyles are the growth centres of the mandible and growth of the mandible influences the overall shape of the face. In growing patients, trauma and pathology of the TMJ effect the condylar development, jaw function and the total morphology of face. In children with TMJ pathologies such as: JIA (Juvenile Idiopathic Arthritis), Hemifacial Microsomia, TMDs, Osteoarthritis, Condylar Fracture, condylar Trauma should be an essential part of the clinical examination and need longitudinal follow-up of used to predict the presence of TMJ related craniomandibular growth abnormalities. Periodic clinical examination of developing patients, early diagnosis and treatment of TMJ pathologies prevents further developmental, functional and esthetical problems in the future.
\end{abstract}

Temporo Mandibular Joint (TMJ) and its normal function are of great importance for the development of the mandible and craniomandibular region [1]. In growing individuals, trauma and pathology of the TMJ has a chronic impact on both the condylar development and the total morphology of the mandible [2]. Over time, the growth under influence of the pathogenesis of the TMJ will be reflected in the soft tissue as a response to the alteration of the function. Congenital deformities and acquired TMJ pathology are the main causes of craniomandibular growth abnormalities, and several of these conditions are well described $[3,4]$.

Temporo MandibularJoint (TMJ) dysfunction in children and adolescents is considered to have a multifactorial etiology [5-7]. Because of the difficulty in establishing a precise etiology, TMJ dysfunction is often defined on the basis of signs and symptoms and channelled into one of the following categories: JIA (Juvenile Idiopathic Arthritis), Hemifacial Microsomia, TMDs, Osteoarthritis, Condylar FractureTrauma. It can be told that the change of condylar morphology in JIA, osteoarthritis, TMD, and trauma patients could be a growth deviation or remodeling of the condyle rather than destruction.

The mandible develops by endochondral ossification of the cartilage situated on the upper part of the condyle. The location of this growth centre is specific for the temporomandibular joint and is responsible for condylar growth [8]. The condyle grows in an upward and forward direction which together with normal mandibular functions, brings the mandible to change its position forward in a rotational movement, bringing the occlusal plane down and creating space for vertical development of the dentoalveolar complex. As much as condylardevelopmentis important factors in mandibular growth, apposition/resorption and normal functional stimulation also plays a role in forming the lowerface [4,9]. Damage to the cartilage of the condylar growth zone, whether of an inflammatory or traumatic origin, can cause a shortening of the condyle and ramus. The posterior face height fails to develop normally, and the resulting posterior vertical deficiency influences the eruption of the teeth and vertical development of the alveolar processes. The soft tissue and muscles will adapt to the short posterior face height and will gradually become more and more difficult to modify by functional options [10].

Juvenile Idiopathic Arthritis (JIA) is the most common autoimmune auto inflammatory musculoskeletal disease in childhood worldwide, manifesting in girls more frequently [11,12]. It is defined as persistent arthritis for more than 6 weeks with an onset at younger than 16 years of age, after excluding other causes of joint inflammation [13]. The etiology is unclear but appears to be multifactorial and may be related to genetic factors associated with triggering events such as psychological stress, abnormal hormone levels, trauma, or infections [14]. All joints can be affected in JIA including the Temporo Mandibular (TMJ). Involvement of the TMJ was first reported in 1897 by still when he described chronic arthritis in childhood [15]. The growth abnormality is described as and consists of condylar growth deviation, short ramus on the affected side, forming of a subangular notch, large gonial angle, large jaw angle and decreased vertical development of the posterior maxilla [4].

Hemifacial Microsomia is the second most common facial birth disorder after cleft lip and palate with an incidence of 1 in 3500 to 6000 live births $[16,17]$. The condition is bilateral in about $10 \%$ of these subjects. The cause is unknown, but the pathogenesis seems to be attributable to damage to the stapedial artery, which can cause hematoma formation in the first and second branchial arches, resulting in abnormal growth and malformation of the mandible. Another theory suggests that the death of neural crest cells can result in dysmorphology of the branchial arches that is similar to that found in hemifacialmicrosomia $[18,19]$. The most important clinical findings in hemifacial microsomia are mandibular malformation with facial asymmetry and microtia. Hypoplasia of the soft tissues, orbital involvement, nerve disorders, and other affected anatomic structures are present with a wide range of variations [20].

Early TMD is a common feature especially in girls at the beginning of puberty. The etiology is not clear but it can be considered caused by factors, such as hypermobility and hormone influence $[4,21,22]$. The maxillary and mandibular length and ramus height have been

${ }^{*}$ Corresponding author: Guhan Dergin, Marmara University Faculty of Dentistry Department of Oral and Maxillofacial Surgery, Buyuk Ciftlik Sk. No: 6 34365, Turkey, Tel: +902122319120; Fax: +902122465247; E-mail: guhandergin@yahoo.com

Received December 29, 2013; Accepted January 03, 2014; Published January 07, 2014

Citation: Dergin G, Aktop S (2014) Temporomandibular Joint Disorders in Children and Related Comorbidities. J Arthritis 3: e110 doi:10.4172/2167-7921.1000e110

Copyright: @ 2014 Dergin G, et al. This is an open-access article distributed under the terms of the Creative Commons Attribution License, which permits unrestricted use, distribution, and reproduction in any medium, provided the original author and source are credited. 
found to be influenced by TMJ disk abnormalities. Disk displacement of the temporomandibular joint with TMJ pain, the symptom was associated with radiographic signs of disk displacement in $77 \%$ to $94 \%$ of the subjects studied in both adult and pediatric patients [23-28]. The incidence of painful disk displacement peaks during puberty; the risk of development of the condition in the teenaged years is 4 times greater than the risk later in life $[29,30]$.

Osteoarthritis or degenerative joint disease of theTMJ is attributed to articular cartilage failure. It develops as a result of a complex interaction of multiple factors. Direct trauma to the mandible producing condylar fractures, sub condylar fractures, other mandibular fractures, or no fractures has been implicated as one of the initiating factors of osteoarthritis. Trauma to the mandible can induce a joint effusion acutely [31,32]. Harris et al. studied 13 patients who had sustained trauma to the mandible and found abnormal uptake in their TMJ scintiscans [33]. Yun and Kim described evidence of acute synovitis, such as fibrillation and ecchymosis, with arthroscopic examination of patients who had mandibular fractures not directly involving the condyles [34]. Furthermore, cytological and biochemical analysis from the synovial fluids of these patients demonstrated the presence of degenerated cells, inflammatory cells, crystals, and a considerable amount of pain-related mediators, such as prostaglandin E2 and leukotriene B4. Also, Seligman and Pullinger showed in a multiple stepwise logistic regression analysis that trauma history is a moderate differentiating feature in patients with intracapsular TMJ disorder [35]. Due to the complex and multifactorial etiology of this particular disease process, the actual incidence of osteoarthritis directly related to trauma to the mandible is difficult to determine, especially in traumatic events that do not result in fractures [31]. The existing literature reports a wide range. It has been estimated that in anywhere from 9 to $85 \%$ of patients, condylar fractures result in degenerative disease of the TMJ [36]. The clinical presentation of patients with posttraumatic TMJ osteoarthritis is non-discernable from TMJ osteoarthritis of other etiologies. The predominant symptoms include constant preauricular pain, with or without radiation, and crepitus. Other symptoms and signs are TMJ clicking, popping, locking, and deviation on opening [31,37].

Pediatric bone fracture is a particular pathology because it occurs on a rapidly growing bone. The management of mandibular fractures in children continues to be a subject of many debates because of its effect on mandibular growth and on temporomandibular Joint (TMJ) mobility. Falls, sports-related injuries, and road traffic accidents are the most frequent causes of facial injuries in children [38]. Usually, pediatric mandibular and alveolar fractures are managed according to the same basic principles applied to adult fractures. Some authors advocated for conservative approach only in maxillofacial trauma in pediatric age group [39,40]. Fracture of the condyle is often followed by remodeling and a disturbance in the development of ramus height and mandibular body length, forankylosis of the TMJ, growth disturbances can be seen in most cases and can be severe [4]. Condylar Fractures (CFs) were seen in about 3 out of 4 cases $(76.0 \%)$ of mandibular fractures in children aged less than 5 years, whereas the number of this type of fracture decreased to $50 \%$ in patients aged $13-15$ years. In most cases $(83.2 \%)$, only one condyle was concerned. Furthermore, Thorén et al. found the site of the condylar fracture to be age related, with a preponderance of intracapsular fractures (58\%) in patients less than 6 years old. In contrast, most of the older children sustained extracapsular fractures, i.e., fractures of the condylar neck (78\%) or in the subcondylar region (4\%) $[41,42]$. Asymmetrical mandibular growth has been observed in about $25 \%$ of children who have sustained condylar fractures [30]. The development of mandibular asymmetry is thought to result from growth disturbance from either injury to the condylar cartilaginous cap or from disruption in function due to ankylosis and hypomobility. If growth is disrupted, the affected ramus height is decreased, resulting in a shorter facial lower third, while the unaffected side grows normally. Also, the chin will deviate toward the affected side. Furthermore, dental compensations, crossbites on the ipsilateral side and hypereruption of the teeth on the contralateral side, producing an occlusal can't, will eventually occur to re-establish a functional occlusion [31].

Temporo Mandibular Joint (TMJ) ankylosis in children is uncommon and one of the most difficult and complex problems managed by oral and maxillofacial surgeons. Trauma, radiotherapy, surgical excision of TMJ tumors, infection, and systemic disease can all results in mandibular hypomobility [43-46]. Trauma can result in an intra-articular haematoma leading to fibrosis, excessive bone formation, and ultimately to hypomobility of the joint [47]. Several authors have postulated that intra-articular haematoma alone may lead to ankylosis of the TMJ based on organisation and subsequent ossification of an intracapsular haematoma [47-52], as Oztan et al. concluded that trauma causing haemorrhage in the joint space may not give rise to ankylosis as it does not always progress to form bone [53]. The region of the TMJ can also become infected from local sites such as otitis media and mastoiditis, or through haematogenous spread from diseases such as tuberculosis, gonorrhoea, and scarlet fever [47].

The soft tissue and muscles are normal in arthritis patients whereas patients with HFM have several tissues included in the abnormality. This might be the reason for difficulties in treating HFM both functionally and surgically [11]. It can be debated whether HFM is a progressive disease becoming more severe over the passage of time or if there is a certain, although abnormal, growth in the area. In the postnatal TMJ pathology there is a potential for condylar remodeling and thereby growth. This is the basis for the possibility of treating with functional appliances [4].

Asymmetries and retrognatism developing from TMJ pathology can be treated beneficially with a combination of functional appliances and distraction osteogenesis. The acquired postnatal condylar deformity has the potential for remodeling which can be used during treatment. The congenital or prenatal condylar abnormalities do not demonstrate remodeling ability without interventions directly. However, it seems to be possible to treat these deformities with functional appliances although in individual cases where the potential for remodeling is less, distraction osteogenesis is an option to obtain sufficient bone length [4].

Condyle is the growth centres of the mandible and growth of the mandible influences the overall shape of the face. In growing patients, trauma and pathology of the TMJ effect the condylar development, jaw function and the total morphology of face. JIA (Juvenile Idiopathic Arthritis), hemifacialmicrosomia, TMDs, osteoarthritis, condylar fracture, conylar Trauma should be an essential part of the clinical examination and need longitudinal follow-up of used to predict the presence of TMJ related craniomandibular growth abnormalities. Therefore, early diagnosis and treatment of TMJ pathologies prevents further developmental, functional and esthetical problems in the future.

\section{References}

1. Laskin DM (1995) The clinical diagnosis of temporomandibular disorders in the orthodontic patient. Semin Orthod 1: 197-206.

2. Kaneyama K, Segami N, Hatta T (2008) Congenital deformities and developmental abnormalities of the mandibular condyle in the temporomandibular joint. Congenit Anom (Kyoto) 48: 118-125. 
3. Murray JE, Kaban LB, Mulliken JB (1984) Analysis and treatment of hemifacialmicrosomia. Plast Reconstr Surg 74: 186-199.

4. Pedersen TK, Sven Erik Norholt SE (2011) Early Orthopedic Treatment and Mandibular Growth of Children with Temporomandibular Joint Abnormalities. Semin Orthod 17:235-245.

5. Egermark-Eriksson I, Carlsson GE, Magnusson T (1987) A long-term epidemiologic study of the relationship between occlusal factors and mandibular dysfunction in children and adolescents. J Dent Res 66: 67-71.

6. Vanderas AP (1994) Relationship between oral parafunctions and craniomandibular dysfunction in children and adolescents: a review. ASDC J Dent Child 61: 378-381

7. Miller VJ, Bodner L (1997) Temporomandibular joint dysfunction in children. In J Pediatr Otorhinolaryngol 38: 215-225.

8. Enlow DH, Hans MG (1996) Growth of the Mandible: Essential of Facia Growth. Philadelphia, W. B. Saunders, 57-78.

9. Moss ML, Rankow RM (1968) The role of the functional matrix in mandibular growth. Angle Orthod 38: 95-103.

10. Pedersen TK, Grønhøj J, Melsen B, Herlin T (1995) Condylar condition and mandibular growth during early functional treatment of children with juvenile chronic arthritis. Eur J Orthod 17: 385-394.

11. Meazzini MC, Mazzoleni F, Gabriele C, Bozzetti A (2005) Mandibular distraction osteogenesis in hemifacialmicrosomia: long-term follow-up. J Craniomaxillofac Surg 33: 370-376.

12. Hayward K, Wallace CA (2009) Recent developments in anti-rheumatic drugs in pediatrics: treatment of juvenile idiopathic arthritis. Arthritis Res Ther 11:216.

13. Hashkes PJ, Laxer RM (2005) Medical treatment of juvenile idiopathic arthritis JAMA 294: 1671-1684

14. Weiss JE, llowite NT (2005) Juvenile idiopathic arthritis. PediatrClin North Am 52: 413-442, vi.

15. Yasser Mohammed, Ola Saeed b, Nayera Zaghloul, Sahar Samer, Samah Mahmud, et al. (2012) Juvenile idiopathic arthritis and the temporomandibular joint, Alex J Med.

16. Murray JE, KabanLB,Mulliken JB, Evans CA. (1985) Analysis and treatment of hemifacialmicrosomia. In: Caronni EP, editor. Craniofacial surgery. Boston: Little, Brown and Company, 377-90.

17. Poswillo D (1974) Otomandibular deformity: pathogenesis as a guide to reconstruction. J Maxillofac Surg 2: 64-72.

18. Poswillo D (1973)The pathogenesis of first and second branchial arch syndrome. OralSurg Oral Med Oral Pathol 35:301-28.

19. Johnston MC, Bronsky PT (1991) Animal models for human craniofacia malformations. J Craniofac Genet DevBiol 11: 277-291.

20. Zanardi G, Parente EV, Esteves LS, Louro RS, Capelli J Jr (2012) Orthodontic and surgical treatment of a patient with hemifacialmicrosomia. Am J Orthod Dentofacial Orthop 141: S130-139.

21. Hirsch C, John MT, Stang A (2008) Association between generalized join hypermobility and signs and diagnoses of temporomandibular disorders. Eur J Oral Sci 116: 525-530.

22. Lee DG, Kim TW, Kang SC, Kim ST (2006) Estrogen receptor gene polymorphism and craniofacial morphology in female TMJ osteoarthritis patients. Int J Oral MaxillofacSurg 35: 165-169.

23. Katzberg RW, O'Mara RE, Tallents RH, Weber DA (1984) Radionuclide skeleta imaging and single photon emission computed tomography in suspected internal derangements of the temporomandibular joint. J Oral Maxillofac Surg 42: 782-787.

24. Katzberg RW, Tallents RH, Hayakawa K, Miller TL, Goske MJ, et al. (1985) Internal derangements of the temporomandibular joint: findings in the pediatric age group. Radiology 154: 125-127.

25. Roberts CA, Katzberg RW, Tallents RH, Espeland MA, Handelman SL (1988) Correlation of clinical parameters to the arthrographic depiction of temporomandibular joint internal derangements. Oral Surg Oral Med Oral Pathol 66: 32-36.

26. Sanchez-Woodworth RE, Katzberg RW, Tallents RH, Guay JA (1988)
Radiographic assessment of temporomandibular joint pain and dysfunction in the pediatric age-group. ASDC J Dent Child 55: 278-281.

27. Paesani D, Westesson PL, Hatala M, Tallents RH, Kurita K (1992) Prevalence of temporomandibular joint internal derangement in patients with craniomandibular disorders. Am J Orthod Dentofacial Orthop 101: 41-47.

28. Katzberg RW, Westesson PL, Tallents RH, Drake CM (1996) Orthodontics and temporomandibular joint internal derangement. Am J Orthod Dentofacial Orthop 109: 515-520.

29. Ribeiro RF, Tallents RH, Katzberg RW, Murphy WC, Moss ME, et al. (1997) The prevalence of disc displacement in symptomatic and asymptomatic volunteers aged 6 to 25 years. J Orofac Pain 11: 37-47.

30. Paesani D, Salas E, Martinez A, Isberg A (1999) Prevalence of temporomandibular joint disk displacement in infants and young children. Oral Surg Oral Med Oral Pathol Oral RadiolEndod 87: 15-19.

31. Giannakopoulos HE, Quinn PD, Granquist E, Chou JC (2009) Posttraumatic temporomandibular joint disorders. Craniomaxillofac Trauma Reconstr 2: 91 101.

32. Hettinga DL (1980) III. Normal Joint Structures and their Reactions to Injury. J Orthop Sports PhysTher 1: 178-185.

33. Harris SA, Rood JP, Testa HJ (1988) Post-traumatic changes of the temporomandibular joint by bone scintigraphy. Int J Oral Maxillofac Surg 17: 173-176.

34. Yun PY, Kim YK (2005) The role of facial trauma as a possible etiologic factor in temporomandibular joint disorder. J Oral Maxillofac Surg 63: 1576-1583.

35. Seligman DA, Pullinger AG (1996) A multiple stepwise logistic regression analysis of trauma history and 16 other history and dental cofactors in females with temporomandibular disorders. J Orofac Pain 10: 351-361.

36. Ellis E 3rd (1998) Complications of mandibular condyle fractures. Int J Ora Maxillofac Surg 27: 255-257.

37. Norman JE (1982) Post-traumatic disorders of the jaw joint. Ann R CollSurgEng 64: $29-36$

38. Glazer M, Joshua BZ, Woldenberg Y, Bodner L (2011) Mandibular fractures in children: analysis of 61 cases and review of the literature. Int $\mathrm{J}$ Pediatr Otorhinolaryngol 75: 62-64

39. Rémi M, Christine MC, Gael P, Soizick P, Joseph-André J (2003) Mandibula fractures in children: long term results. Int J Pediatr Otorhinolaryngol 67: 25-30.

40. Maniglia AJ, Kline SN (1983) Maxillofacial trauma in the pediatric age group. Otolaryngol Clin North Am 16: 717-730.

41. Thorén H, lizuka T, Hallikainen D, Lindqvist C (1992) Different patterns of mandibular fractures in children. An analysis of 220 fractures in 157 patients. Craniomaxillofac Surg 20: 292-296.

42. Thorén H, lizuka T, Hallikainen D, Nurminen M, Lindqvist C (1997) An epidemiological study of patterns of condylar fractures in children. $\mathrm{Br} \mathrm{J}$ Oral Maxillofac Surg 35: 306-311.

43. Proffit WR, Vig KW, Turvey TA (1980) Early fracture of the mandibular condyles: frequently an unsuspected cause of growth disturbances. Am J Orthod 78: 1-24

44. Kaban LB, Bouchard C, Troulis MJ (2009) A protocol for management of temporomandibular joint ankylosis in children. J Oral Maxillofac Surg 67: 19661978

45. Topazian RG (1964) Etiology of Ankylosis of Temporomandibular Joint: Analysis of 44 Cases. J Oral Surg Anesth Hosp Dent Serv 22: 227-233.

46. Kaban LB, Troulis MJ (2004) Pediatric Oral and Maxillofacial Surgery. Philadelphia, PA, WB Saunders, p 469

47. Kaban LB, Perrott DH, Fisher K (1990) A protocol for management of temporomandibular joint ankylosis. J Oral Maxillofac Surg 48: 1145-1151.

48. Ferretti C, Bryant R, Becker P, Lawrence C (2005) Temporomandibular joint morphology following post-traumatic ankylosis in 26 patients. Int $\mathrm{J}$ Oral Maxillofac Surg 34: 376-381.

49. Miller GA, Page HL Jr, Griffith CR (1975) Temporomandibular joint ankylosis: review of the literature and report of two cases of bilateral involvement. J Oral Surg 33: 792-803. 
Citation: Dergin G, Aktop S (2014) Temporomandibular Joint Disorders in Children and Related Comorbidities. J Arthritis 3: e110 doi:10.4172/2167$7921.1000 \mathrm{e} 110$

Page 4 of 4

50. el-Mofty S (1972) Ankylosis of the temporomandibular joint. Oral Surg Oral Med Oral Pathol 33: 650-660.

51. Meng FW, Zhao JL, Hu KJ, Liu YP (2009) A new hypothesis of mechanisms of traumatic ankylosis of temporomandibular joint. Med Hypotheses 73: 92-93.
52. Güven O (2000) A clinical study on temporomandibular joint ankylosis. AurisNasus Larynx 27: 27-33.

53. Oztan HY, Ulusal BG, Aytemiz C (2004) The role of trauma on temporomandibular joint ankylosis and mandibular growth retardation: an experimental study. J Craniofac Surg 15: 274-282. 